\title{
Objectifying user attention and emotion evoked by relevant perceived product components
}

\author{
R. Schmitt ${ }^{1}$, M. Köhler ${ }^{1}$, J. V. Durá ${ }^{2}$, and J. Diaz-Pineda ${ }^{2}$ \\ ${ }^{1}$ Laboratory for Machine Tools and Production Engineering WZL, Chair of Metrology and Quality \\ Management, RWTH Aachen University, Steinbachstr. 19, 52074 Aachen, Germany \\ ${ }^{2}$ Institute of Biomechanics of Valencia (IBV), Universitat Politècnica de València, Camino de Vera s/n, \\ 46022 Valencia, Spain \\ Correspondence to: M. Köhler (m.koehler@wzl.rwth-aachen.de)
}

Received: 7 January 2014 - Revised: 8 October 2014 - Accepted: 10 November 2014 - Published: 3 December 2014

\begin{abstract}
A company's aim is to develop products that engage user attention and evoke positive emotions. Customers base their emotional evaluation on product components that are relevant for their perception. This paper presents findings of both identifying relevant product components and measuring emotions evoked by relevant perceived product components. To validate results, the comparison with self-reporting methods identifies similarities and differences between explicit expressed and implicit recorded customer requirements. On the one hand, eye tracking is applied to deduce the attention provoked by perceived product components. In order to link the product strategy with product components, the paper presents results considering the fact that the gaze track is affected by current thoughts. (Köhler et al., 2013, 2014a, b; Köhler and Schmitt, 2012) On the other hand, since self-reporting tools are only useful for obtaining information about the conscious part of customers' emotions, there is a need for measurement methods that measure the changes in physiological signals (bio-signals). Arousal is similar to emotional intensity and is related to the galvanic skin response. Positive or negative emotions are defined by the valence that is measured by facial electromyography. Findings are presented that relate changes in bio-signals on the aesthetical design to the global product impression as well as to emotions and, subsequently, linking changes in physiological signals to the evaluation of semantic concepts and design parameters. The presented approach provides conclusions and valid information about products as well as product components that provoke certain emotions and about product components linked to a certain product concept, which could be part of a product strategy. Consequently, hard facts and special design rules for emotional product design can be deduced.
\end{abstract}

\section{Introduction and motivation}

Since the perception of products is linked to emotions and emotions affect the purchasing decision, it is crucial for the success of a company to measure customers' attention and emotions objectively and integrate this awareness into processes of emotional product design. It should be the aim to develop products that engage user attention and evoke positive emotions since customers of the target group base their emotional evaluation on product components that they perceive relevant. This paper presents approaches to systematically survey and objectify that information about the customer's subjective product perception and attention, as well as the emotional evaluation. Perceived quality is one decisive factor for the purchasing decision of almost all types of products. However, human perception is highly complex and cannot be measured efficiently only by customer surveys. Nearly $80 \%$ of all information that is crucial for people's decisions is gathered by the eye (Berghaus, 2005). The developed approach focuses on the visual aspects of perception, since those affect the registration of a bulk of cognitive information. The challenging task is the objectified measurement of attention and related emotions arising while a product is observed. 


\section{Perceived product quality and emotions}

\subsection{Perceived quality}

The improvement of perceived product quality has become an important determinant in order to stand out from competing companies (Falk et al., 2008). Perceived quality is a subjective and very individual interpretation of product realizations. In order to understand a customer's perception of product quality, the understanding of different levels of perception is of importance (Falk et al., 2008). The customer first perceives an overall impression of the product that is formed by the customer's individual product evaluation. Thereby, the overall impression of the product often corresponds to the system level of the whole product. On this level, the information about, for instance, customer's feelings and product perception is rather subjective. Perception clusters are one level more detailed and formed by different quality attributes that the customers merge on sensory perception such as harmonious aspects in optics. In order to further identify and structure the product, one or several descriptors are defined for each quality attribute. With these descriptors, technical specifications can be described in a very specific way by partial comparisons with terms the customer is familiar with. Finally, the combination of different characteristics of a descriptor with corresponding readings makes it possible to objectively determine relevant technical parameters. The active design of technical parameters again influences each level of perception. Consequently, special metrology is required to gather objective information of specific design parameters and to ensure a harmonious and high-value visual appearance of the product design towards customer's perception. With regard to product development and design, already in early steps of product development, there is a need to create and to ensure products and product attributes that evoke a high quality perception. Therefore, a structured approach to quality perception from the customers' perspective should be systematically applied to survey and to specify product attributes that are relevant to the perception and attention in order to objectify the customer's quality judgments (see Fig. 1 and Falk et al., 2008). Especially during early steps of product development process (PDP), there is a potential to concentrate on objectively measuring the visual impression of products and quality attributes (e.g., by using eye tracking), since it is often more decisive than other impressions (e.g., haptic, acoustic) to evoke emotions (Duchowski, 2007).

\subsection{Emotions and purchase decisions}

Emotional product development and design - often synonymously referred to a affective engineering (Nagamachi, 2011; Jiao et al., 2006) - are based on the fact that emotions play an essential role in purchasing decisions (Beaujean et al., 2011; Köhler et al., 2013). Those methodologies aim at integrating or typifying emotions and perception in the PDP.

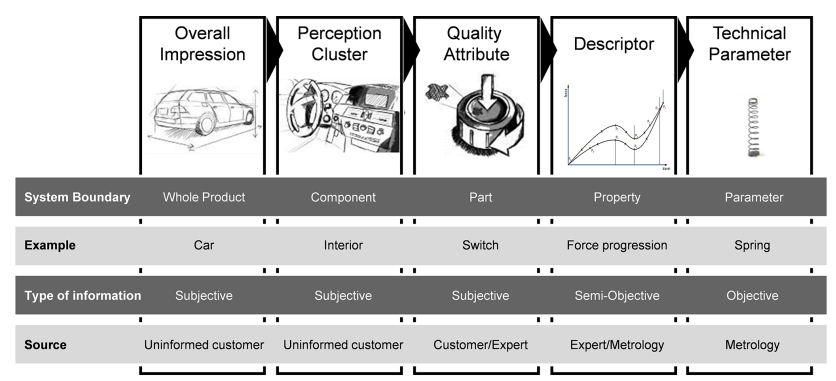

Figure 1. Structured approach towards quality perception referring to Falk et al. (2008).

Therefore research on factors that help to objectify the purchase decision is essential for fact-based product management (Hofer and Mayerhofer, 2010). With a successful realization of the conceptual conversion of customer requirements into technical product characteristics, the customer's perceived product quality can be improved. Hence, the earlier the needs of customers are defined and converted into technical characteristics, the smaller the costs and duration of PDP are and the more the purchasing decision can be affected in a positive way, which leads to higher revenues and profits for the company (Beaujean et al., 2011).

Users' perception of any product or service can be obtained by analyzing their feelings. It is very common to use questionnaires in order to measure customer opinion. The methods based on questionnaires translate the answers of the customers into parameters related to the product. However, these methods use the subjective opinion of the customer, and the subjective opinion depends on individual circumstances. These methods have several shortcomings. It is possible that the customer will change their answer deliberately because they prefer to hide their feelings, and it is also possible for the costumer to get confused because the differences between products are very subtle (Laparra-Hernández et al., 2009). The experimenter can influence the customer and change their answer too (Czerwinski et al., 2001; Nielsen and Levy, 1994). Finally, it is important to consider that unconscious processes are involved when the customer makes a decision (Tversky and Kahneman, 1973). An example of unconscious process is the stress level of the customer. Stress is a common component when we make decisions and can influence the opinion (Regueiro and León, 2003).

\subsection{Established methods and concepts for objectifying perceived quality}

Quality function deployment (QFD), conjoint analysis, means-ends analysis and Kansei engineering are some established concepts that try to objectify perceived quality data for integration in emotional engineering. Basically, these concepts lack the ability to quantify emotions through measuring physiological signals. QFD hinders the quantification 
of qualitative information (Hawlitzky, 2002). Since conjoint analysis premises information about product features that determine people's preference valuation a priori, the definition of relevant product characteristics in particular is difficult with regard to innovative product ideas (Meffert, 2000; Sattler, 2006). Means-ends analysis only focuses on the cognitive view but disregards the significant activating and emotional aspects (Kroeber-Riel and Weinberg, 1996). Kansei engineering quantifies customers' emotions and perception extensively but in general only focuses on the description of customers' impressions by semantic concepts and disregards unconscious impressions (Schütte, 2002).

\subsection{Measuring emotions}

Emotions can be measured in different ways as either discrete categories or continuous dimensions. Desmet (2002) proposed seven negative emotions (anger, contempt, disgust, indignation, dissatisfaction, disagreement and boredom) and eight positive emotions (desire, pleasure, surprise, inspiration, amusement, admiration, satisfaction and fascination) related to product appearance. However, there are many possible classifications and the classification can be difficult. The relation between categories and physiological signals is not clear. Therefore, the dimensional approach was chosen. Emotions can be represented in a space of two dimensions: valence and arousal. Whether an emotional response is positive or negative, it is represented by the dimension valence. In the category of EMG (electromyography) measures, facial EMG measures are often applied to objectify emotion recognition (valence). Facial EMG can detect small changes in emotions even when the facial expression does not change (Cacioppo et al., 1990). Cacioppo et al. (2004) concludes that the muscles most involved in emotion detection are the corrugator supercilii (related to frowning), the zygomaticus major and the depressor anguli oris (both related to smiling). GSR (galvanic skin response) measures changes in the electrical skin conductance and is related to the level of arousal (Lang et al., 1993). Arousal characterizes elicitation of emotion and emotion intensity. Thus, for the understanding of product perception, facial EMG and GSR have a potential use (Laparra-Hernández et al., 2009). For these reasons, facial EMG and GSR are the most suitable bio-signals for applying the dimensional appraisal in order to distinguish between product design alternatives.

\section{Objectifying user attention and emotion}

This paper presents results of a comprehensive approach for objectifying user evaluation of product alternatives and product components, especially regarding user attention and the emotional behavior via analyzing bio-signals. The methodology investigates which products and which product attributes are important to the customer and how an arrangement of parts impresses the customer the most and fits best with the aligned product strategy and the customer's emotional feelings. The general objective is the improvement of perceived quality. In the process of product design and development it is important to gather educated information for the comparison between the global impression of product alternatives as well as for the decision in favor of one specific alternative. Furthermore it is important to focus on the most relevant quality attributes since the resources of time and costs are limited. Additionally, the relation between semantic concepts and relevant product components should be pointed out. In order to not only have relied on subjective data derived from questionnaires, the objectification of emotions is of significant importance. Therefore the differences in emotions while changing design parameters should be investigated and the relation between the semantic concepts and the emotions analyzed.

\subsection{Research questions and general methodology}

Derived from the presented state of the art and from the challenges of perceived quality and of emotional (Beaujean et al., 2011; Köhler et al., 2013) or affective engineering (Nagamachi, 2011), the following research questions are of importance:

First, concerning user attention, it is important to investigate the following questions:

1. Which are the most relevant components according to the visual cognitive impression of products?

2. How can eye tracking be applied in order to measure the relevant components in an objective way?

3. Do semantic concepts, or product strategies, have any influence on the attention of the user toward the most important product components?

Secondly, regarding the emotional evaluation during the process of product design, it is crucial to investigate

1. whether bio-signals are able to allow for distinguishing between product alternatives with regard to the overall product impression,

2. whether semantic concepts have any influence on emotions concerning special design alternatives.

The following methods are applied in order to investigate which product attributes customers subjectively perceive and what the customer really feels, as well as how this feeling influences the product evaluation:

- methodical collection of product strategies,

- gathering conscious product evaluation and decisions between design alternatives through use of questionnaires, 
- identification of the most important components of a special product design with regard to user attention,

- applying semantic concepts to differentiate between design alternatives on global product impression as well as on a more detailed level of product attributes,

- applying eye tracking to investigate the user attention related to the aforementioned methods,

- measuring bio-signals with a two-dimensional approach (GSR, EMG) to objectify the emotional response

\subsection{Experimental design and analysis procedure}

The presented methodology was applied in several corresponding studies during the research project CONEMO (e.g., Köhler et al., 2013, 2014a, b). In this paper, results are presented with consideration of a case study on an optically refined SUV (sport utility vehicle). Since the refined car was modified with a body kit, it differs a lot with regard to the detailed level of quality attributes from its production model (Köhler and Schmitt, 2012).

\section{Previous work: collection and reduction of semantic concepts}

A holistic study of semantic concepts was conducted in advance. Several methods were applied in order to generate an overview of words that are related to the emotional description of the studied SUV. Afterwards, the company's point of view and the customers' perspective were aligned and the words systematically reduced. Four of the most important semantic concepts describing the product strategy are used for illustration: dynamic, powerful, sporty and modern.

For reasons of study design, and to reduce systematic influences on the results of eye tracking, the products were presented at the same angle and size and with the same background. In preliminary studies an investigation found that the length of time each picture should be presented is dependent on the type of product and the product complexity. For examining the exterior design of cars, the presentation of pictures for between 10 and $15 \mathrm{~s}$ was researched in previous studies of the presented approach in order to record data about the attention and the emotional response of the user. A time of $11 \mathrm{~s}$ for recording bio-signals was chosen in order to reduce the size of the files of bio-signals and the computing time. For both the serial model and the refined car, the exterior front of the car was subdivided into about 20 visible parts as well as clusters (e.g., the bumper, headlights, rims) by means of the structured approach towards quality perception (see Sect. 2 and Köhler and Schmitt, 2012).

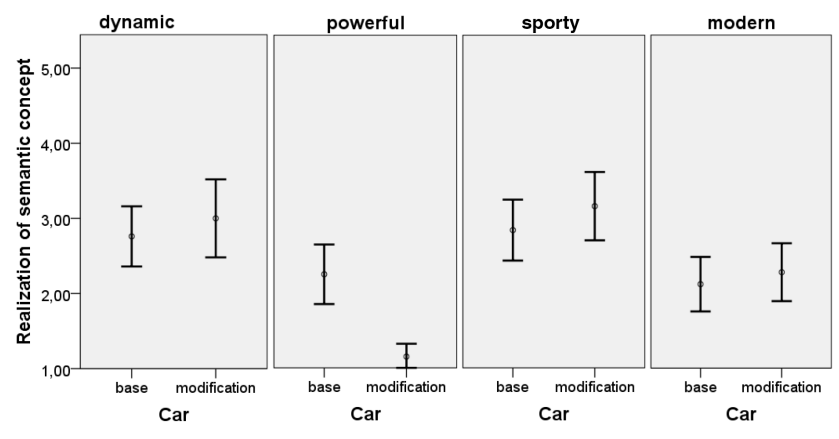

Figure 2. $95 \%$ confidence interval - articulated evaluation of the realization of semantic concepts.

\subsubsection{Capturing user attention with regard to product components}

To deduce the attention provoked by perceived product components, a study with a screen-based eye-tracking system was performed. In order to link the product strategy with the product components, the theory that the gaze track is affected by current thoughts was used and applied (Yarbus, 1967). In this study, 25 automobile enthusiasts participated (18 to 27 years; mean: 21.4 years). Eye tracking was combined with ordinary questionnaires in order to contrast results of explicit and implicit user opinion.

A five-point Likert scale (1: strongly agree; 2: agree; 3: don't know; 4: disagree; 5 : strongly disagree) was used to ask how the semantic concepts had been realized in one of the two product alternatives on the level of overall impression (see Fig. 2). ANOVA revealed only a significant difference concerning "powerful" $(F=28.209, P=0.000)$. A post hoc paired $t$ test showed that the refined car is evaluated as significantly more powerful than the serial model. These results only rely on the articulated opinion of users about the global impression (subjective source of information). Since there is no relation to special product attributes, it is hard to draw conclusions with regard to product design about manipulative design possibilities.

\section{Capturing the most relevant product attributes}

The participants were explained the eye-tracking experiment and the procedure. The study was conducted in an appropriate surrounding that assured, for example, constant light conditions and reduction of noise. The system was a screenbased combined pupil/corneal reflection system with the advantage that slight head movements do not lead to loss of the gaze track. Furthermore, the subject does not have any direct contact to the system. The study started with calibration and it was ensured the participant's eyes were maintained at a distance of about $60 \mathrm{~cm}$ from the monitor. Then, each alternative was presented without any comment (free interaction) for a duration of $15 \mathrm{~s}$. The aim was to capture the areas of interest from the customer's point of view that are linked to 

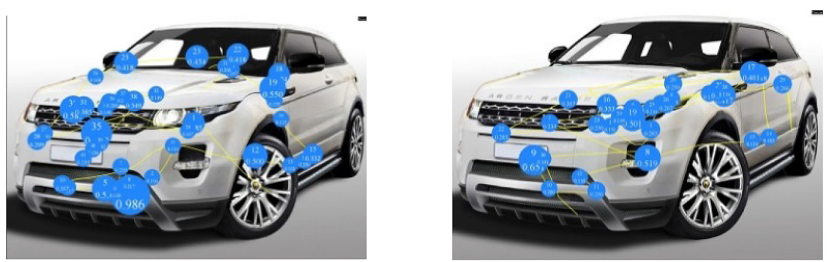

Figure 3. Individual gaze track for one user (free interaction vs. dynamic).

detailed product attributes or even more complex clusters of perception. All data were expressed in time ratios (dependent variables), since eye tracking is a relative measurement system and since the presented approach aims to compare the influence of different factors (independent variables) (Köhler et al., 2013). The time ratios were calculated by dividing the time a specific attribute was observed by the total time the product was observed (areas that do not belong to the car exterior such as the background of the picture were excluded). Pareto analysis was applied in order to focus on the most relevant product components.

\section{Measuring the influence of semantic concepts on user's attention}

Eye tracking was applied with the objective of relating biosignals and responses with regard to quality attributes with the feelings and needs that are represented by semantic concepts. First, each participant was presented a slide with an introduction slide where Think in dynamic (that means the semantic concept dynamic) was written on it. Afterwards, a set of two pictures representing the refined and the serial model were shown. The duration of presenting the pictures was decreased after the free interaction because the subjects were already familiar with both product alternatives. Both the fixation time (expressed in time ratios) for each component (about 20 visible parts of the car exterior; see Sect. 3.2) and the gaze tracks representing the gaze while thinking about a certain product concept which was priorly introduced by the introduction slide were recorded (see Fig. 3). Besides these data, relevant information for user attention can also be deduced by analyzing the order of fixation and the frequency of fixating on an area of interest during a specific period of time.

\section{Statistical methods}

A within-subjects ANOVA was conducted in SPSS to compare the effect of semantic concepts on the time ratio of relevant quality attributes. For the significant effects, post hoc analysis of paired $t$ tests was done and educated recommendations for product design were derived. The objective of the eye-tracking study was mainly to lead to valid information about which quality attribute the customers consciously and
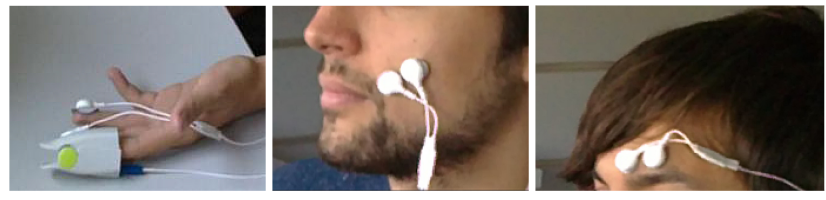

Figure 4. Placement of sensors for detecting bio-signals.

unconsciously relate to a certain semantic concept. To survey whether the customers' evaluation is positive or negative, the emotions also have to be investigated.

\subsubsection{Bio-signals experimental design}

Once the relevance of product components is known, the emotional response related to specific design alternatives should be objectified. Fourteen male undergraduate students (age from 18 to 30 years) took part in the study, with a single session lasting about half an hour. Again, the participants were explained the experiment (e.g., the procedure and the duration). In order for the participant's eyes to be maintained at a distance of $61 \mathrm{~cm}$ from the $17 \mathrm{in}$. monitor, adjustments were made (Laparra-Hernández et al., 2009). The EMG sensors were attached to the left corrugator and zygomatic muscles of the face, and the GSR sensors were attached to the middle and ring fingers of the left hand (see Fig. 4).

Two sets of pictures were used: the first set was used to adapt the participants to the experiment environment and to reduce the effect of surprise. The pictures used correspond to three different products: a fan, a lamp and a living room scene. The second set of pictures was the two car design alternatives. The subjects were instructed to examine the three pictures ( $6 \mathrm{~s}$ each). Then, the two car pictures were examined for $11 \mathrm{~s}$ (see duration concerning eye-tracking study). The aim of this step is to record the emotional responses without evaluating a particular semantic concept. After having been shown a question (semantic concept), the subject again examined the pictures and answered the question (using the Likert scale). This procedure allowed for identifying whether the bio-signals are influenced by a semantic concept. The order of questions and pictures was randomized in order to avoid potential ordering effects. Immediately before a picture was displayed to the user, a black slide was displayed for $10 \mathrm{~s}$. For one thing, this additional slide separates the responses between pictures and, consequently, minimizes the impact of signals elicited by consecutive pictures. For another, the time span was applied to normalize the subject's response by inducing a state of relaxation (Laparra-Hernández et al., 2009).

\section{Signal processing}

EMG and GSR signals were processed offline; the processing technique is based on that used in other studies (LaparraHernández et al., 2009; Heino et al., 1990): on the one hand, 
the signals of EMG were fully rectified and filtered $(2 \mathrm{~Hz}$ low-pass filter) to acquire the envelope and to eliminate fast changes. On the other hand, the GSR signal is characterized by two components: a fast fluctuation (phasic) and a slow component (tonic). The tonic component is the baseline level of skin conductance in the absence of any particular environmental event. The phasic component is more event-related, with fast changes (peaks) interpreted as responses to a specific stimuli, and is related to the arousal level. Furthermore, the GSR signal was filtered using a fifth Butterworth lowpass filter (cut-off frequency of $0.05 \mathrm{~Hz}$ ) (Laparra-Hernández et al., 2009; Heino et al., 1990).

As done in the study for capturing the attention (see Sect. 3.2.1), each picture type (products and product associated with a semantic concept) is analyzed individually. To avoid transitory effects, the beginnings of all signals were discarded. First, EMG and GSR values are normalized to compare the values of each type of product for each subject. Two-step normalization process is used, with different possibilities. The first step is represented in Eq. (1), where $S$ can be the 75th percentile of the signal during the entire exposure time of each image. The variables calculated with this criterion have the suffix _MV. Otherwise $S$ can be the 75 th percentile of the signal during a fixed time $(6 \mathrm{~s})$ for all the products. The variables calculated with this criterion have the suffix_MF (Laparra-Hernández et al., 2009).

$N s_{n j}=\frac{\hat{S}-\hat{R}}{\hat{R}}$,

where $n$ is the subject and $j$ is the picture.

$R$ can be the 75th percentile of the signal in the $10 \mathrm{~s}$ (black slide) before exposure to each stimulus. The variables calculated with this criterion have the suffix _ni_. Otherwise $R$ can be the mean of the first three relaxations. At the beginning of the test there are three relaxations (three black slides) with three stimuli different to the evaluated products. These relaxations are done before asking the subject about any concept and are not affected by the previous history. Therefore $R$ is the mean of the three 75th percentiles of the signals in the $10 \mathrm{~s}$ (black slide) before exposure to each stimulus. The variables calculated with this criterion have the suffix _net.

Secondly, for each user the signals are normalized again with respect to the maximum value recorded for the user in question. The second normalization $\left(N_{n j}\right)$ is carried out according to Eq. (2), where $N_{S n j}$ is the normalized value (with the step) of the signal that is elicited by picture $j$ from subject $n . N_{S n}$ is a vector with the normalized values of the signals, elicited by all pictures, from subject $n$ (Laparra-Hernández et al., 2009):

$N_{n j}=\frac{N_{S n j}-\min \left(N_{S n}\right)}{\max \left(N_{S n}\right)-\min \left(N_{S n}\right)}$,

where $n$ is the subject and $j$ is the picture.
Table 1. Time ratio for the most relevant product attributes.

\begin{tabular}{lrr}
\hline Item & Mean & SD \\
\hline Name & 0.069 & 0.0722 \\
Rims & 0.069 & 0.0427 \\
Headlight_left & 0.067 & 0.0562 \\
Engine hood & 0.115 & 0.0742 \\
Windshield & 0.095 & 0.0696 \\
Side_door & 0.089 & 0.0704 \\
Grill & 0.131 & 0.0823 \\
Bumper & 0.179 & 0.0897 \\
\hline
\end{tabular}

\section{Statistical methods}

The analysis of the signal processing was performed with Octave and the statistical analysis with the statistics software R. To detect differences in the bio-signals (EMG and GSR), the univariate ANOVA was applied (LaparraHernández et al., 2009). The model applied is bio-signal $\sim$ CAR_TYPE + CAR_TYPE:CONCEPT, where bio-signal is the independent variable, CAR_TYPE is a factor and CAR_TYPE:CONCEPT is an interaction. Our model does not include CONCEPT as a factor because CONCEPT is a question about the product (CAR_TYPE). We consider that any influence of the question should be related to the product.

\subsection{Results}

As described before, differentiation between the investigation of attention and the objectification of emotional evaluation of visually perceived product attributes should be done.

\subsubsection{Capturing user attention related to semantic concepts}

For all subjects and for the two product alternatives the ratio of fixation duration is captured for each of the 20 areas of interest which were defined before (see Sect. 3.2). The Pareto analysis of the free examination of the products revealed that the subjects observed the following attributes more than $80 \%$ of the whole mean time: the bumper (a cluster of perception formed by number plate and bumper bar), the grill, the engine hood, the windshield, the side door, the signature with the name/logo, the rims and the left headlight (see Table 1). Because of the special presentation of the product in the picture, almost all relevant product attributes are located in the front part of the car exterior.

Furthermore, a MANOVA, using the time ratios as dependent variables and the different defined areas of interest as independent variables, shows that there is only a slight significant effect of the car type according to the attention of the most important product attributes (Pillai's trace $=0.580$; $F$ value $=1.936 ; p=0.053)$. Hence, there is no significant difference in the importance of the most relevant product 
Table 2. Results of within-subject repeated-measures ANOVA.

\begin{tabular}{lrlr}
\hline \multicolumn{4}{c}{ Factor semantic concept (five levels) } \\
\hline Car & Pillai's trace & $F$ value & $p$ level \\
\hline Base car & 0.535 & $F(20,284)=2.194$ & 0.003 \\
Modification & 0.657 & $F(20,252)=2.475$ & 0.001 \\
\hline
\end{tabular}

Table 3. Results for the selected quality attributes.

\begin{tabular}{lll}
\hline & \multicolumn{2}{l}{ Car 1: base car (serial model) } \\
\hline Quality attribute & $F$ value & $p$ level \\
\hline Name/signature & $F(4,72)=5.177$ & 0.009 (Greenhouse-Geisser) \\
Headlight left & $F(4,72)=5.055$ & 0.007 (Greenhouse-Geisser) \\
Bumper & $F(4,72)=0.874$ & 0.484 \\
\hline \multicolumn{2}{c}{ Car 2: modification } \\
\hline Quality attribute & $F$ value & $p$ level \\
\hline Name/signature & $F(4,64)=2.483$ & 0.081 (Greenhouse-Geisser) \\
Headlight left & $F(4,64)=3.355$ & 0.015 \\
Bumper & $F(4,64)=5.481$ & 0.004 (Greenhouse-Geisser) \\
\hline
\end{tabular}

attributes, or, in other words, the most important attributes in the design of the refined car were also of similar importance in the design of the serial model. Analyzing the correlations between the time ratios for the different relevant product attributes revealed some weak correlations (Pearson correlation coefficient $>0.20$ ). Obviously there are weak negative correlations between product attributes that are not directly next to each other (e.g., signature/name and bumper: $\left.r_{\text {Pearson }}=-0.411, p=0.003\right)$.

To analyze the effect of semantic concepts on the user's attention, the 25 subjects were shown a set of stimuli: the factor "car" with two levels and the semantic concepts with five levels. The time ratio for each product attribute was recorded with specific interest on the most relevant attributes.

A repeated-measures ANOVA (Table 2), this time using the semantic concepts as independent variables, was conducted to test differences between means of fixation time ratios for significance. From analysis of the cars separately, there was a significant effect of the semantic concept on the time ratio for several relevant product attributes while thinking in semantic concepts (dynamic, powerful, sporty, modern in comparison to free interaction).

For purposes of illustration, the bumper, the signature with the name and the left headlights are selected for reporting results. Since the Mauchly's test of sphericity was not fulfilled $(p<0.05)$ for name and headlight in the case of the serial model car and for name and bumper in the case of the modified car, the Greenhouse-Geisser correction was applied for the $p$ level of univariate tests (see Table 3).

The diagrams for the estimated marginal means for the time ratio of the selected product attributes (Fig. 5) give a first idea of the effect of semantic concepts. For both car
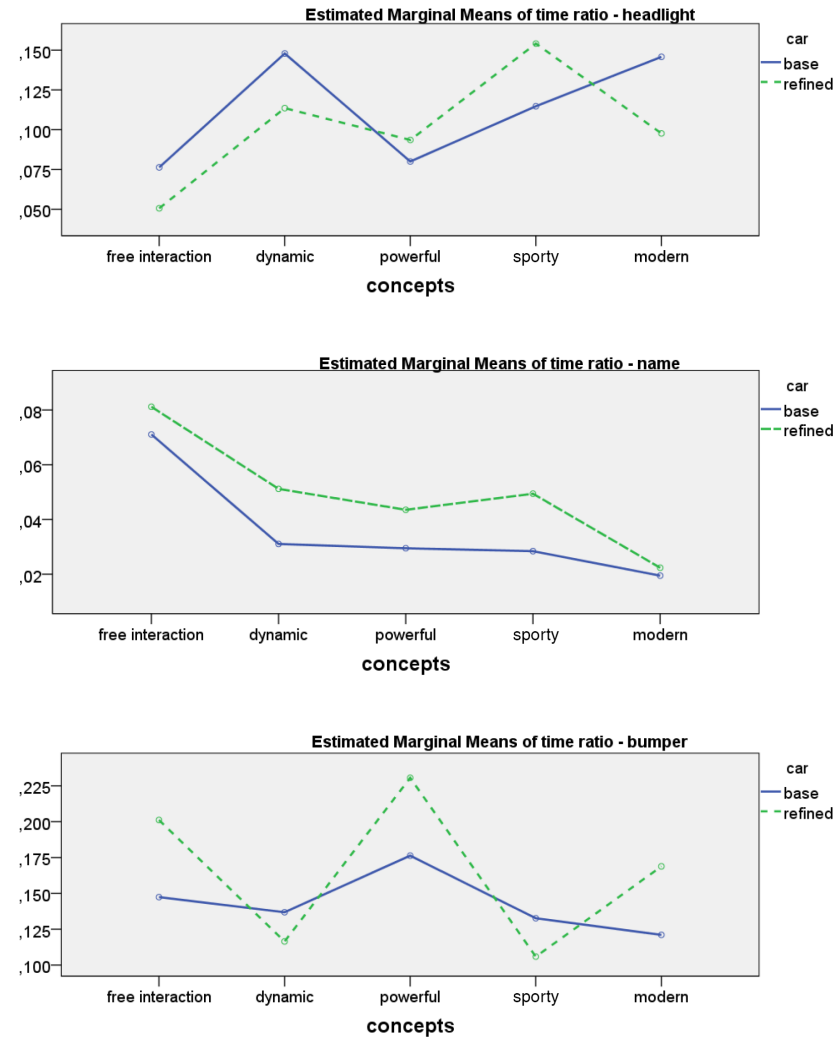

Figure 5. Means of time ratio for left headlight, name and bumper.

alternatives, post hoc pairwise comparisons were used to indicate which semantic concept differs significantly $(p<0.1)$ for both cars. That way, for each product attribute, design recommendations concerning the attention that is evoked by the semantic concepts could be derived.

For instance, it could be concluded that the left headlight of the refined car (green line in Fig. 5) was significantly more focused while thinking in the semantic concepts (e.g., dynamic $(T(24)=3.45, p=0.001)$ or sporty $(T(23)=3.76$, $p=0.0001)$ ) in comparison to the free interaction. Similar results could be found in the case of the serial model car (blue line), except there was no significant difference between the free interaction and "powerful" $(T(18)=0.915, p=0.186)$.

The diagram for the name reveals that the means for each semantic concept are higher in the case of the modified car than for the serial model. Furthermore, considering also slight significant influences in the case of the refined car $(p=0.081)$, there were significant differences between all semantic concepts and the free interaction.

Since, in the case of the serial model car, there was no significant effect of the semantic concepts regarding the time ratio of the bumper ( $p=0.484)$, the interpretation of results is presented for the refined car. Specifically, the bumper was related more to "powerful" than to "dynamic" $(T(18)=2.633$, $p=0.008)$, "sporty" $(T(17)=3.315, p=0.002)$ or "modern" $(T(16)=1.47, p=0.08)$. In combination with the 

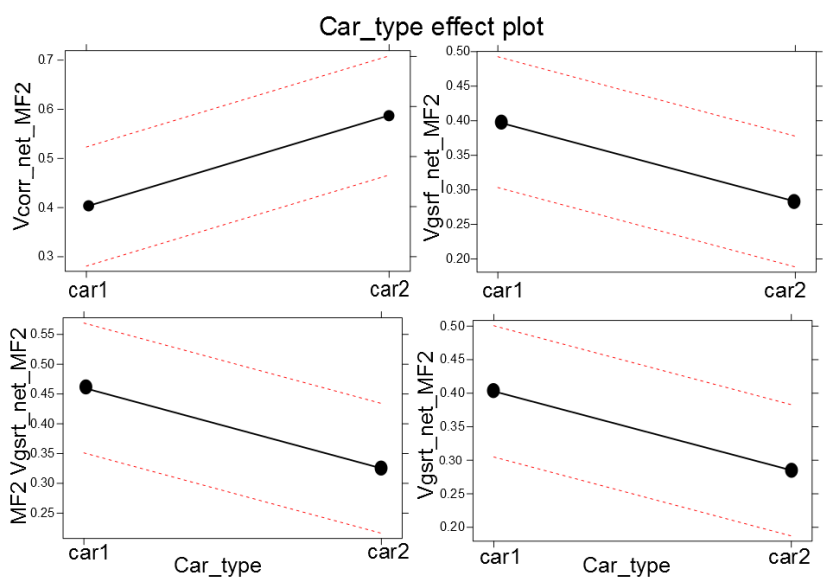

Figure 6. Results of EMG and GSR measures.

Table 4. Bio-signals.

\begin{tabular}{lll}
\hline Variable & Factor & $p$ level \\
\hline Vzig_net_MV2 & Car_type:Concept & 0.0709 \\
Vgsrt_net_MV2 & Car_type & 0.09366 \\
Vcorr_net_MF2 & Car_type & 0.03467 \\
Vgsrf_net_MF2 & Car_type & 0.09067 \\
Vgsrt_net_MF2 & Car_type & 0.08477 \\
\hline
\end{tabular}

self-reporting questionnaire, a possible conclusion could be that the bumper is one important attribute responsible for the refined car to be evaluated as more powerful than the serial model car.

\subsubsection{Measuring bio-signals}

Considering the bio-signals, the significant $(p<0.1)$ effects are shown in Table 4 , where $V_{\text {zig }}$ is the zygomaticus EMG, $V_{\text {corr }}$ is the corrugator EMG, $V_{\text {gsrt }}$ is the tonic component of GSR, and $V_{\text {gsrf }}$ is the phasic component of GSR.

The variables contain the indicator 2 in order to show that they have been normalized according to the two steps described above. No significant differences were found with variables normalized with the first step only, nor when using a normalization with the 75 th percentile of the signal in the $10 \mathrm{~s}$ (black slide) before exposure to each stimulus.

Figure 6 shows that car 1 (serial model) better evokes emotions and more intensely (corrugators low and GSR high) than car 2 (modified model). Considering the interaction effect with the concepts (Fig. 7), it seems that "powerful" is the concept that provokes the highest positive opinion for car 1 , and "dynamic" for car 2.

\section{Discussion}

Findings of a methodology are presented relating changes in bio-signals on the aesthetic design with the global product

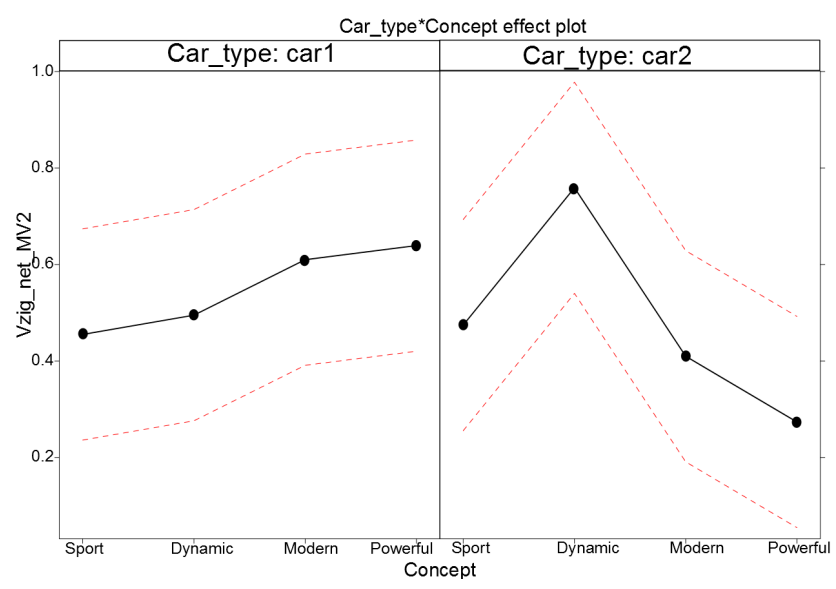

Figure 7. Interaction effects plot.

impression as well as with emotions and, subsequently, linking changes in bio-signals to the evaluation of semantic concepts and design parameters. It was shown that eye tracking and measuring bio-signals can be applied to indicate relevant product attributes and to measure their impact on customer's emotional response. Moreover, the results suggest that semantic concepts affect the individual gaze track and, subsequently, the time ratio for the attention evoked by relevant product attributes. Furthermore, results should be interpreted on a very detailed level of quality attributes in order to link feelings expressed through semantic concepts with the attention measured by means of the time ratio. To match customers' needs and feelings, this awareness is of particular importance in early steps of PDP and can be applied, for example, in product advertisements to attract and to point out special design alternatives or product components. Deeper analysis of the recorded eye-tracking data should be done in order to interpret the significance of why subjects really focus on one component longer than another.

According to the technical analysis of measuring biosignals, it was shown that two-step normalization is more effective than using only one step. This kind of normalization considers for the maximum value recorded for each user and all the images that the subject examines in one session (see also Laparra-Hernández et al., 2009). Significant differences have been found with the normalization with the relaxations (black slides) done before asking the subject about any concept and not affected by the previous history (_net_), whereas no differences were found with the use of the relaxation before stimulus (_ni_). It is assumed that subjects could be thinking about the questions or semantic concepts during the relaxing time, which could be considered as a stimulus. For this reason the relaxing periods before the images had some noise. Therefore, it is better to use a method of relaxation that is not affected by any stimulus, i.e., not an image or concept (mental process). 
Further suggestions according to the experimental design of the preliminary work for conducting the studies of eye tracking and measuring bio-signals can be derived. For one thing, the influence of the order of the presented pictures must be considered as done in further studies (Köhler et al., 2013, 2014a, b). It seems to be important whether or not a random order for each subject leads to data with higher quality regarding the eye-tracking experiment. For another, semantic concepts should be carefully selected in a way that users have a good understanding of the concept. In addition, it is crucial to apply an appropriate level of detail with regard to the product structure, which could also affect the results presented in the methodology. Moreover, it has to be considered that the results of the conducted studies only indicate influences regarding semantic concepts and possibilities concerning eye tracking and EMG/GSR. One specific sample of proper respondents for both kinds of emotional studies should be used in order to apply the same profile of respondents and to derive more significant and valid data. In addition, the number of subjects should be increased to improve the value of results of statistical analysis.

\section{Conclusions and future directions}

The presented approach provides conclusions and valid information about products as well as product components that provoke certain emotions and about product components linked to a certain product strategy. Consequently, the objective is to use that information for enhancing the perceived quality and to derive design rules and recommendations. The results shown are an excerpt of a comprehensive methodology for measuring and objectifying customers' attention and emotions evoked by products and product components as well as the systematic integration of the results into the early product development and design process. This also includes the comparison with self-reporting methods to identify similarities and differences between explicit expressed and implicit recorded customer requirements (Köhler and Schmitt, 2012; Köhler et al., 2013, 2014a, b). The possibility to generalize the methodology for other products on other levels of detail was proved.

Acknowledgements. The paper presents results from the cooperative research project CONEMO (Consumer Evaluation Measurement for Objectified Industrial Use - funded by the CORNET program) of the Laboratory for Machine Tools and Production Engineering (WZL), RWTH Aachen University, Germany, together with the Institute of Biomechanics of Valencia (IBV), Spain. The funding agencies are IMPIVA (operational program FEDER of the Comunidad Valenciana, Spain) and AiF (Germany). The CORNET promotion plan 47EN of the Research Community for Quality (FQS), August-Schanz-Str. 21A, 60433 Frankfurt/Main, was funded by the AiF within the program for sponsorship by Industrial Joint Research and Development (IGF) of the German Federal Ministry of Economic Affairs and Technologies based on an enactment of the German parliament. The authors would like to express their gratitude to all parties involved.

Edited by: R. Tutsch

Reviewed by: two anonymous referees

\section{References}

Beaujean, P., Grob, R., Häfen, K., Köbler, E., Köhler, M., Quattelbaum, B., Schmitt, R., Seitz, R., Wagner, M., and Willach, A.: Emotionale Produktgestaltung - Wert der wahrgenommenen Qualität, in: Proceedings: Tagungsband zum AWK, edited by: Brecher, C., Klocke, F., Schmitt, R., and Schuh, G., Shaker, 2011.

Berghaus, N.: Eye-Tracking im stationären Einzelhandel. Eine empirische Analyse der Wahrnehmung von Kunden am Point of Purchase, dissertation, University Duisburg-Essen, 2005.

Cacioppo, J. T., Tassinary, L. G., and Fridlund, A. J.: The skeletomotor system, in: Principles of Psychophysiology: Physical Social, and Inferential elements, edited by: Caccioppo, J. T. Tassinary, L. G., Cambridge University Press, New York, 325-384, 1990.

Cacioppo, J. T., Bernston, G. G, Larsen, J. T., Poehlmann, K. M., and Ito, T. A.: The psychophysiology of emotion, in: Handbook of Emotions, edited by: Lewis, M. and Haviland-Jones, J. M., The Guilford Press, New York, 173-191, 2004.

Czerwinski, M., Horvitz, E., and Cutrell, E.: Subjective duration assessment: an implicit probe for software usability, in: Proceedings of the IHM-HCI 2001 Conference, Vol. 2, 167-170, 2001.

Desmet, P.: Designing Emotions. Delft University of Technology, Department of Industrial Design, 2002.

Duchowski, A. T.: Eye Tracking Methodology: Theory and Practice, Vol. 2., Springer, London, 2007.

Falk, B., Schmitt, R., and Quattelbaum, B.: Product Quality from the Customers' Perspective - Systematic Elicitation and Deployment of Perceived Quality Information, in: Proceedings of the 6th CIRP-Sponsored International Conference on Digital Enterprise Technology, 216 pp., 2008.

Hawlitzky, N.: Integriertes Qualitätscontrolling von Unternehmensprozessen, Gestaltung eines Quality-Gate-Konzeptes, dissertation, Technical University München, 2002.

Heino, A., Van der Molen, H. H., and Wilde, G. J. S.: Riskhomeostatic processes in car following behaviour: electrodermal responses and verbal risk estimates as indicators of the perceived level of risk during a car-driving task, Report VK 90-22, Traffic Research Centre, University of Groningen, Haren, 1990.

Hofer, N. and Mayerhofer, W.: Die Blickregistrierung in der Werbewirkungsforschung. Grundlagen und Ergebnisse, in: Der Markt, No. 49, 149 pp., 2010.

Jiao, R., Zhang, Y., and Helander, M.: A Kansei mining system for affective design, Journal of Expert Systems with Applications, 30, 658-673, 2006.

Köhler, M. and Schmitt, R.: Systematic Consumer Evaluation Measurement for Objectified Integration into the Product Development Process, in: Advances in Affective and Pleasurable Design, edited by: Ji, Y. G., CRC Press, 503-512, 2012.

Köhler, M., Falk, B., and Schmitt, R.: Objectifying user attention caused by visually perceived product components, in: Proceedings of the 16th International Congress of Metrology, doi:10.1051/metrology/201314002, 2013. 
Köhler, M., Falk, B., and Schmitt, R.: Applying Eye-Tracking in Kansei Engineering Methodology for Design Evaluations in Product Development, KEER conference, Linköping, available at: http://dqi.id.tue.nl/keer2014/papers/KEER2014_125 (last access: 30 September 2014), 2014a.

Köhler, M., Falk, B., and Schmitt, R.: Integrating User Attention for Design Evaluations in Customer-Orientated Product Development, in: Advances in Affective and Pleasurable Design, edited by: Ji, Y. G. and Choi, S., Proceedings of the 5th International Conference on Applied Human Factors and Ergonomics AHFE 2014, 19-23 July 2014, CRC Press, 428-439, 2014 b.

Kroeber-Riel, W. and Weinberg, P.: Konsumentenverhalten, Vol. 6, Vahlen, 1996.

Lang, P. J., Greenwald, M. K., Bradley, M. M., and Hamm, A. O.: Looking at pictures: affective, facial, visceral, and behavioral reactions, Psychophysiology, 30, 261-273, 1993.

Laparra-Hernández, J., Belda-Lois, J. M., Medina, E., Campos, N., and Poveda, R.: EMG and GSR signals for evaluating user's perception of different types of ceramic flooring, Journal of Industrial Ergonomics, 39, 326-332, 2009.
Meffert, H.: Marketing. Grundlagen marktorientierter Unternehmensführung, Vol. 9, Gabler, 2000.

Nagamachi, M.: Kansei/Affective Engineering, CRC Press, Florida, 2011.

Nielsen, J. and Levy, J.: Measuring usability: preference vs. performance, Communications of the ACM 37, No. 4, 66-75, 1994.

Regueiro, R. and León, O.: Estrés en desiciones cotidianas, Journal of Psicothema, 15, 533-538, 2003.

Sattler, H.: Methoden zur Messung von Präferenzen für Innovationen, Zeitschrift für betriebswirtschaftliche Forschung (zfbf), Vol. 54/06, 154-176, 2006.

Schütte, S.: Designing Feelings into Products. Integrating Kansei Engineering Methodology in Product Development, dissertation, University Linköping, 2002.

Tversky, A. and Kahneman, D.: 1 Availability: a heuristic for judging frequency and probability, Cognitive Psychol., 5, 207-232, 1973.

Yarbus, A. L.: Eye Movements and Vision, Plenum Press, 1967. 